\title{
Capitalismo y globalización: El capital en la era del capital tecnológico
}

\author{
Camila Arbuet Osuna*
}

\begin{abstract}
Artículo recibido: 26 de febrero de 2014
Artículo aprobado: 9 de abril de 2014

Doi: dx.doi.org/10.12804/desafios26.02.2014.04

Para citar este artículo: Arbuet Osuna, C. (2014). Capitalismo y globalización: El capital en la era del capital tecnológico. Desafíos, 26 (2), 97-124. doi: dx.doi.org/10.12804/desafios26.02.2014.04
\end{abstract}

\section{Resumen}

Pensar el último proceso de globalización desde la tradición marxista supone considerar qué elementos del análisis clásico (de las formas de conformación y reproducción del mercado mundial) sirven aún para comenzar una explicación sobre las condiciones actuales de existencia y cuáles se han vuelto caducos. La obra cumbre de Marx, El capital, publicada en 1867, presentaba explicaciones solventes para un mundo que ingresaba en su fase imperialista, cuyo capital financiero comenzaba a perfilarse como determinante y cuyos Estados se consolidaban como grandes potencias coloniales, que poseían una clase obrera activa con más de un programa revolucionario. La derrota del proyecto socialista, la complejización y volatilización de las características clásicas de las clases sociales, la reconfiguración del imperialismo en una forma tanto más eficaz. y capilar de dominación, las ulteriores revoluciones tecnológicas y la consolidación del capital tecnológico, como la nueva llave del mercado mundial, exponen a la vieja teoría a las inclemencias de la historia. Nuestra pregunta es entonces: de las hipótesis clave de esta matriż ¿qué elementos siguen en pie como herramientas de análisis y cuáles ban

\footnotetext{
* Becaria doctoral del Consejo Nacional de Investigaciones Científicas y Técnicas (Conicet) en la Universidad Nacional de Quilmes, Buenos Aires, Argentina. Docente de Teoría Política y Filosofía Política en la Universidad Autónoma de Entre Ríos, Paraná, Entre Ríos, Argentina. Correo electrónico: camila_arbuet@hotmail.com
} 
pasado a ser parte de la historia de la economía política? Este trabajo se propondrá responder este interrogante.

Palabras clave: Capitalismo, globalización, Marx, actualización.

\title{
Capitalism and Globalization: Das Kapital in the Era of Technological Capital
}

\begin{abstract}
To reflect on the last process of globalization from a Marxist tradition demands that we sort through the elements in the classical analysis (dealing with the rise and reproduction of a world market) in order to determine which ones can still prove useful for attempting an explanation of our present conditions of existence, and which ones have become outdated. Marx's main contribution Das Kapital offered convincing explanations for a world that was entering its imperialist phase: a world in which finance capital was emerging as a key determinant, in which states were consolidating into big colonial powers with an active working class guided by more than one revolutionary program. The collapse of the socialist project, the increasing volatility and complexity of the defining features of the working class, the reconfiguration of capitalism towards much more effective forms of capillary domination, the subsequent technological revolutions, and the consolidation of technological capital as the key element within the world market threaten to expose the old theory to the inclemency of history. Considering the key assumptions of this list: which elements remain useful tools for analysis and which ones belong to the history of political economy? This article tries to answer this question.
\end{abstract}

Keywords: Capitalism, Globalization, Marx, update.

\section{Capitalismo e globalização: O capital na era do capital tecnológico}

\begin{abstract}
Resumo
Pensar o último processo de globalização a partir da tradição marxista supõe considerar quais são os elementos da análise clássica (das formas de configuração e reprodução do mercado mundial) que servem ainda hoje para iniciar uma explicação acerca das condições atuais de sua existência e quais ficaram ultrapassados. A obra-prima de Marx, O capital, publicada em 1867, apresentava explicacões pertinentes para um mundo que entrava em sua fase imperialista, onde o capital financeiro comencava a
\end{abstract}


emergir como algo determinante e cujos Estados eram considerados como grandes potências coloniais, que possuiam uma classe operária ativa com mais de um programa revolucionário. A derrota do projeto socialista, a complexidade e volatilização das características clássicas das classes sociais, a reconfiguração do imperialismo numa forma mais eficaz e capilar de dominio, as posteriores revoluções tecnológicas e a consolidação do capital tecnológico, assim como a nova chave do mercado mundial, expõem a velha teoria à severidade da bistória. Nossa pergunta é a seguinte: dentre as hipóteses chave desta matriz, qué elementos continuam em pé como ferramentas de análise e quais já passaram a fazerparte da história da economia politica? Este trabalbo terá o propósito de responder a esta questão.

Palavras chave: Capitalismo, globalização, Marx, atualização.

La historia nos ha enseñado que todas las teorías tienen fecha de vencimiento. En el caso del marxismo, el último de los Grandes Relatos, hemos de decir que, en cuanto matriz explicativa, ha roto todos los récords temporales, ya que aún aporta ejes para comprender el desarrollo de las relaciones sociales. Esto se debe tanto a la increíble capacidad de prognosis de Marx, que pudo captar buena parte del progreso de la lógica del capital a escala global a partir de los elementos de su etapa germinal, como al variopinto alud de pensadores que siguieron las huellas, más que de un pensamiento, de un modo de pensar, que reavivaron las tesis clásicas al calor de los nuevos acontecimientos y sensibilidades. Sin embargo, los años pasan para todo y es imprescindible que aquella gran virtud que siempre tuvo el marxismo, me refiero a su vínculo con la vitalidad de la política, se preserve y muestre los alcances y los límites actuales su teoría política.

Sería una tarea imposible para la extensión que propone un artículo desarrollar las hipótesis más fuertes que aventura explícitamente El capital, pero sí es posible reducir taquigráficamente el corazón del texto a unas cinco proposiciones fundamentales sobre la caracterización del sistema capitalista: 1) los intercambios mercantiles que lleva adelante la lógica del capital terminan necesariamente en el fetichismo de la mercancía, que es una propiedad de dicha lógica. 2) Existe una propensión a la igualación de la tasa media de ganancia, en cuanto que la invención tecnológica — imitada por la competencia — da una ventaja 
circunstancial. 3) La reproducción del capital necesita la transformación de parte del excedente social (plusvalía) en capital. 4) Hay una tendencia por la cual las ramas económicas más concentradas arrastran el excedente de las menos concentradas y generan la constitución del oligopolio y el monopolio. 5) Podemos encontrar un adentro del mercado mundial y un afuera del mercado mundial que le hace resistencia y que es el resultado de formas históricas anteriores.

Sobre este cuadro general analizaremos las rupturas y las continuidades que la rápida metamorfosis del capital ha impuesto, en este último medio siglo, a las condiciones de existencia: al trastocar las relaciones sociales y las identidades de clase, al erosionar la importancia de los Estados más allá de su papel de garantes de la relaciones de producción, al generar nuevos sujetos (que formatean su deseo de acuerdo con la lógica de la mercancía), al modificar la naturaleza de muchas formas de disidencia política y la concepción misma de poder. La propuesta de este trabajo, por lo tanto, es cotejar las proposiciones marxistas expuestas con las condiciones de existencia de esta nueva última y particular globalización reponiendo la pregunta política por excelencia, ¿qué hacer?, ¿cómo pensar la política en estas circunstancias?, ¿cuáles son los espacios de resistencia que se abren, cuáles son las fisuras, en este nuevo sistema? Comencemos por analizar la vigencia de la primera proposición y sus posibilidades de actualización.

\section{Uno. Continuidad y complejización de "el fetichismo de la mercancía"}

La forma mercancia y la relación de valor de los productos del trabajo en que esa forma cobra cuerpo, no tiene absolutamente nada que ver con su carácter físico ni con las relaciones materiales que de este carácter se derivan. Lo que aqui reviste, a los ojos de los hombres, la forma fantasmagórica de una relación entre objetos materiales no es más que una relación social concreta establecida entre los mismos hombres.

Karl Marx, El capital

La mediación de los vínculos interpersonales por las mercancías, que parecieran tener una entidad propia por fuera de las relaciones humanas que las hacen existir, no solo se ha sostenido sino que ha escalado a 
grados increíbles. La ocupación del espacio espectral en el que debiera estar inscrito, así sea simbólicamente, el productor por la pura exposición de la mercancía bajo sus propias reglas de mostración, ha sido eyectada a nuevas escalas por la propaganda. En ella se muestra una mercancía, en su necesario sistema de relaciones con otras, envuelta por una cadena de signos sociales inequívocos, desprovista de cualquier vínculo con el trabajo que la hizo posible. Rodeando al objeto solo se encuentra la promesa, siempre renovada, de la felicidad: entendida como la evasión de la muerte y, principalmente, del sinsentido. El trabajo tiene mala prensa, quizás porque todos al menos sospechan que detrás de casi toda trasnacional la explotación ha alcanzado niveles tan demenciales como exorbitantes son sus tasas de ganancia, posibilitadas por las leyes de flexibilización laboral, la desregulación estatal y la descentralización de la producción en las comunidades pobres de todo el mundo; quizás por la alienación intrínseca al trabajo en el capitalismo. El olvido de esta situación, como del resto de relaciones sociales opresivas que mantienen funcionando el consumo (el ejemplo obvio es el de las reglas del patriarcado en la venta de productos de limpieza y belleza), es la función de la propaganda, la actual encargada de que funcione la suspensión de la credibilidad que toda gran ficción requiere. Esta situación de creciente anomia que abre el fetichismo de la mercancía se vio potenciada, además, por la terrible pérdida de las antiguas formas de intercambio y solidaridad que el quiebre de todo horizonte social común trajo aparejado, después de las tumultuosas décadas de los setenta, ochenta y noventa.

Esto ha llevado a que algunos argumentos de las resistencias apelen a la vulnerabilidad compartida como elemento aglutinante, en medio de un mar de sujetos disociados, tratando de hacer consciente no la igualdad, pero sí la paridad de nuestra exposición a los regímenes de explotación y regulación del capital (al partir de la situación de nuestros propios cuerpos). Darse esta estrategia, en medio de la gran fragmentación que poseen las luchas políticas actuales, supone dejar de ver a ese Otro — sublimado más que yo en la mostración mercantil— como

1 Obviamente esta perspectiva siempre es relativa. 
un Otro que cuestiona mis condiciones de existencia (Butler, 2006), principalmente de consumo, y pasar a verlo como un Otro que comparte la resistencia contra su formateo como mercancía.

Por un lado, el fetichismo de la mercancía, unido con la mercantilización del cuerpo, ha lesionado sensiblemente la capacidad de indignación; por el otro, la diferenciación social entre el valor de una vida y otra ha llegado a grados inenarrables. Sin embargo, hay quienes sostienen que si bien el fetichismo de la mercancía sigue en plena vigencia, es incompatible con la fetichización de las personas, y el argumento esgrimido para sostener esta hipótesis, que ha contribuido al relego del análisis de esta gran proposición marxista, es el siguiente:

No podemos decir que en las sociedades en las que la producción para el mercado es la que predomina —en último término, en las sociedades capitalistas - "con el hombre sucede lo mismo que con las mercancías" [cita de El capital. Precisamente lo opuesto es lo verdadero: el fetichismo de la mercancía acontece en las sociedades capitalistas, pero en el capitalismo, las relaciones entre los hombres no están claramente "fetichizadas"; lo que hay son relaciones entre gente "libre" y cada persona sigue su propio interés egoísta. La forma predominante y determinante de las relaciones entre las personas no es la dominación y la servidumbre, sino un contrato entre personas libres que son iguales a los ojos de la ley. El modelo es el intercambio de mercado: dos sujetos se encuentran y su relación carece de las trabas de la veneración al Amo, del patrocinio y del cuidado del Amo por sus súbditos; se encuentran como dos personas cuya actividad está cabalmente determinada por sus intereses egoístas: cada quien procede como un bien utilitario; la otra persona está despojada para cada quien de toda aura mística; todo lo que ve cada quien en su socio es a otro sujeto que sigue su interés y que a él solo le interesa en la medida en que posea algo - una mercancía — que pueda satisfacer algunas de sus necesidades (Žižek, 2003, p. 52).

Slavoj Žižek cae, en esta afirmación, en la trampa liberal de la igualdad de posibilidades abstractas y parece, en este aferro a las condiciones 
formales, olvidar las múltiples limitaciones que este ideal, "iguales ante los ojos de la ley", tiene. No se trata de negar la revolución que esta igualdad civil supuso frente a la dominación del Antiguo Régimen, sino de no relegar sus evidentes restricciones en un mundo profundamente desigual social y económicamente. El engaño que marcaba Marx que suponía la igualación de una mercancía con otra (como objetos que valen lo mismo) es ilustrativamente analogable al engaño que supone la igualación de una persona con otra: en ambos casos, esta igualación es necesaria para el intercambio (económico o político), pero encubre los signos de la diferencia: en el último caso de clase, sexo, raza, credo, etc. Por lo tanto, una cosa es que necesitemos de su universal para hacer la convivencia posible (cuestión que es opinable, pero claramente la ficción política por la que todos somos libres e iguales es mejor que las otras que hemos experimentado) y otra muy distinta es que naturalicemos este universal olvidando su carácter ficcional, convencional y represivo.

Por otra parte, no es preciso que haya una relación entre amo y esclavo para que la mediación mercantil le otorgue a alguna de las partes, como prolongación de la mercancía que exhibe, un aura mística. Baste ver los dandys que aparecen en los comerciales de autos o las féminas de las propagandas de perfumes para percibir la mistificación de esos cuerpos suprahumanos: sin problemas, sin marcas, sin poros. Podemos decir que el vínculo entre las personas no se fetichiza (todo lo contrario: se devalúa), pero claramente los cuerpos han sufrido la prolongación del fetichismo de la mercancía y se han convertido en objetos fetiches: "la mesa baila", diría Marx; "las estrellas de cine de sesenta años no tienen arrugas", diríamos nosotros.

En el plano de las relaciones laborales, si la mercancía en cuestión es la fuerza de trabajo, el contrato claramente sirve como parte de la fetichización (al naturalizar el desplazamiento del valor del tiempo de trabajo por el valor de la mercancía, invisibilizando la plusvalía), como señala Marx (2000):

El contrato mediante el cual [el trabajador] vendía su fuerza de trabajo parecía resultar de un acuerdo entre dos voluntades libres, 
la del vendedor y la del comprador. Concluido el negocio, se descubre que el trabajador no era libre, que el tiempo por el cual puede vender su fuerza de trabajo es el tiempo por el que está obligado a venderla (p. 169).

El trabajador, en sentido amplio — ya obviamente no estamos hablando del proletariado-, tiene - tanto en carácter de vendedor como de comprador - limitada su libertad por las necesidades, materiales y simbólicas, que impone el capital. Y estas últimas son tan importantes como las primeras en un sistema donde la subsistencia pasa también por la pertenencia que garantiza la posesión de ciertos signos (generalmente, encarnados en mercancías).

Finalmente, la réplica de Žižek a Marx tiene otro punto de fuga cuando sostiene que un individuo se relaciona con el otro exclusivamente para obtener la mercancía que necesita para satisfacer sus necesidades. Básicamente ¿qué sería una mercancía que pueda "satisfacer las necesidades"? Debemos aclarar que estamos hablando de un tipo de mercancía particular, una mercancía relacionada con las necesidades básicas, ya que muchas de ellas solo generan mayores y nuevas necesidades. Esto nos lleva a otro punto: la fetichización de las personas es tal que una mercancía puede tener valor solo porque esa persona en particular la posee, y puede perder su valor poco tiempo después de que nos apoderamos de ella. La propaganda ha comprendido y explota esa propensión con siniestra brillantez.

\section{Dos. Refutación de la tendencia al equilibrio de la tasa media de ganancia, debido a la mutación del capital tecnológico}

En la época en la cual escribe Marx impera el capital industrial, que el economista Pablo Levín llama capital no diferenciado. Para este tipo de capital la innovación técnica suponía una verdadera ventaja que, sin embargo, se veía aplanada por la lógica misma de la acumulación: cada tanto la tasa de ganancia debía enfrentarse con el aumento de la composición orgánica del capital, cayendo, y esta tendencia se intentaba contrarrestar con la reducción de salarios (capital constante), el 
abaratamiento de los servicios sociales que vienen con el salario, el aumento de rotación del capital y la innovación tecnológica. Cuando esta última se producía en estas condiciones críticas, claramente era un obstáculo para la igualación de las tasas de ganancia pero, como lo señala Levín (1997):

[...] en el marco del capital no diferenciado este impedimento es accidental y temporario. Es aleatorio, ya que cada empresa de capital tiene en abstracto la misma probabilidad de adquirir el privilegio de la innovación. Y es temporario, pues el innovador, tarde o temprano, deberá resignarse a perder su privilegio, sea porque no pudo impedir la entrada de imitadores u oferentes de sucedáneos próximos, sea porque él mismo organizó el negocio de la difusión controlada y pudo resarcirse cobrándoles un peaje a las empresas adoptadoras, un canon por derechos cedidos, una tarifa por servicios de apoyo, jugando él el papel de licenciador, y los adoptadores el de clientes y licenciatarios de contratos de "tecnología" (p. 332).

Desde mediados del siglo pasado esto ya no es así. Lo que se ha denominado tercera ola de la globalización (Toffler, 1981) ha hecho del capital tecnológico el elemento decisivo de la acumulación. La innovación tecnológica ha perdido su carácter extraordinario para volverse ventaja permanente, en ramas determinantes de la producción, como la informática, lo que cualquier consumidor de tecnología electrónica sabe por experiencia directa.

La revolución que ingresó el capital tecnológico en la era de la informática supuso, entre otras cosas, una reconfiguración radical, en los centros de gestación de dicho capital, de las formas de trabajo. En dichos centros observamos un retorno a algunas de las libertades que el artesano solía tener antes de ingresar a las fábricas: el trabajo colectivo y la valoración de la imaginación, allí donde la aparente horizontalidad configura la forma de trabajo del puñado de personas encargadas de sostener la interminable y vertiginosa carrera por diferenciar cada vez más abismalmente las tasas de ganancias entre las empresas. Vemos entonces la apuesta por cierto tipo de formación de capital humano 
en un punto de exigencia del mercado mundial en el que un invento define la propulsión exorbitante de ciertas compañías y la sepultura de tantas otras. Muchas veces, en esta carrera queda expuesta patentemente la supeditación del valor de uso al valor de cambio de este nuevo tipo de mercancías tecnológicas, en las que la innovación tiene un valor en sí mismo; mientras que el sentido, su "utilidad", lo seguirá otorgando la lógica del consumo capitalista en sus versiones renovadas.

Tomemos el ejemplo de Facebook: Mark Zuckerberg inventa en 2004 un programa que explota uno de los deseos más intensos de la sociedad contemporánea: el de aparecer en lo que masivamente ha pasado a configurarse como el espacio público, de ser vistos, ansia que Guy Debord había analizado tempranamente en su obra prima: La sociedad del espectáculo (1967). La primera gran certeza que tiene el inventor de Facebook es que está frente a una base de datos que se cargará sola, porque es una vía de depositación de esa incontenible necesidad social. Tal necesidad la podríamos describir como una herida masiva al narcisismo, de la cual la diferenciación del mercado se embebe: hay una casta de selectas personas que aparecen en los mass media y una gran mayoría que no. Facebook crea la sensación de que esa barrera se ha roto: de que hay nuevamente "comunidad", entendida de una forma un tanto escueta como el libre acceso a la publicitación de su privacidad (privilegio exclusivo de los "famosos").

Facebook es uno de esos inventos cuya masividad e impacto (en primera instancia en la transformación de las relaciones intersubjetivas) hacen que valga en sí mismo, más allá de su utilidad. Eso explica por qué incluso cuando no se sabía bien qué se podía hacer con esta nueva tecnología, esta ya valía miles de millones. Pero ahí no se termina el asunto. Cuando el grupo encargado de Facebook averigua que su rentabilidad no está, como en el caso de Google, asociada con las ventas de otras mercancías, sino con la obtención de la información en cuanto mercancía (Facebook es posiblemente la mayor red de relevamiento de lo que Raymond Williams llama estructura de sentimientos de la sociedad actual, no solo del consumo), la comprensión de las 
nuevas condiciones de hegemonía del capital tecnológico se dispara nuevamente: la capacidad de circulación define el valor de Facebook. Actualmente, esta comunidad tiene 1230 millones de habitantes. Si lo pensáramos como un país, sería el tercer país más poblado del mundo, ese es su valor.

Como algo completamente inusitado: Facebook, en cuanto vendedor de información, extrae el plusvalor del tiempo de ocio, es decir, de la lucha contra el sinsentido que la cotidianeidad de millones de personas supone; es cierto que es un privilegio tener tiempo de ocio; pero aún más es tener algún deseo que lo guíe. Todavía en 1965 Althusser (2004) podía sostener que:

Se tiende a hablar de "mutación" o "revolución" en la tecnología contemporánea. En realidad, Marx había afirmado desde el Manifiesto, y demostrado en El capital, que el modo de producción capitalista se caracteriza por una "revolución ininterrumpida en los medios de producción", ante todo en los instrumentos de producción (tecnología). Algo que viene sucediendo desde hace ciento cincuenta años es declarado "sin precedente" en grandes proclamaciones, y es verdad que desde hace algunos años las cosas van mucho más rápido que antes. Pero se trata de una simple diferencia de grado, no de naturaleza. Toda la historia del capitalismo es la historia de un prodigioso desarrollo de la productividad a través del desarrollo de la tecnología (p. 27).

Esta afirmación ya no es posible. Con el capital tecnológico, el capitalismo ha mutado de naturaleza; no se trata de la velocidad de la innovación, sino de su carácter y del impacto que, sobre las espaldas del capital financiero, esta nueva lógica ha señalado. Los resultados de la nueva hegemonía se pueden ver en cualquier lugar: según la famosa revista económica Forbes, las tres empresas más valiosas del mundo son Apple, Google e IBM. En total, su cotización bursátil llega a los 441.276 millones de dólares. En resumen: todo lo que nace en el capital diferenciado es barrido por el capital tecnológico y lo que no nace allí es barrido por la apropiación del excedente de plusvalía. 


\section{Tres. La extracción del excedente social (plusvalía) del trabajador}

Innegablemente, lejos de extinguirse, esta necesidad estructural del capitalismo no ha hecho más que acentuarse, modificando eficazmente las condiciones de extracción de la plusvalía. Luego de la derrota del movimiento obrero, que había comenzado paradójicamente con las divisiones internas provocadas por las políticas sociales de Bismark y con el fervor nacionalista de la etapa imperialista para terminar con las masacres de los años sesenta y setenta, las formas de regulación del trabajo se hicieron más funestas. Los mecanismos de control explícito se volvieron paulatinamente menos necesarios, dado que los engranajes estatales y privados que movía el capital, con su salvaje diferenciación, hicieron que los mismos sujetos garantizaran diferencialmente su explotación. En otras palabras, el capital nos enseñó que hay un modo de explotación particular para cada tipo de trabajador y, lo más alarmante de la cuestión, que dicho aprendizaje es posible gracias a una serie de prácticas naturalizadas, a las que los sujetos están expuestos desde la más tierna infancia, que garantizan que cada persona detecte la forma de explotación que el capital necesita ella.

Evidentemente, las formas de extracción de la plusvalía a una obrera maquiladora de Ciudad Juárez no son las mismas que las de un gerente de la Coca-Cola en Buenos Aires; pero ambos comparten una exposición —claramente desigual-a las técnicas biopolíticas capitalistas que, lejos de agotarse en la regulación impuesta en el lugar de trabajo, se constituyen íntimamente durante toda una vida, cardinalmente de la mano de las grandes instituciones que desde siempre custodian el capital: la familia, el Estado, la religión y el capital mismo.

En el punto dos veíamos cómo el capital tecnológico era decisivo en la ruptura de la tendencia hacia la igualación de las tasas de ganancia. Para, en cambio, Michel Foucault el factor determinante en la reversión de esta tendencia es en realidad el desarrollo del capital humano, del cual el capital tecnológico en última instancia depende. En su seminario de 1979, compilado como Nacimiento de la biopolítica, Foucault (2007) nos dice, siguiendo la línea de neoliberales que retomaron las 
hipótesis de Joseph Schumpeter (sobre la influencia de la innovación en la diferenciación terminante de las tasas de ganancia):

No es posible detenerse en ese problema de la innovación y confiar, de alguna manera, en la intrepidez del capitalismo o el estímulo permanente de la competencia para explicar el fenómeno correspondiente. Si hay innovación, es decir, si se encuentran cosas nuevas, si se descubren nuevas formas de productividad, si hay invenciones de tipo tecnológico, no es más que la renta de cierto capital, el capital humano, o sea, el conjunto de inversiones que ha hecho el hombre en el mismo (p. 272).

El desarrollo de este "capital humano" que Foucault explica por diversos factores que podríamos asociar con la vida buena, en un sentido pleno (necesidades básicas enteramente cubiertas, afecto, estimulación desde la infancia, educación, etc.), está íntimamente asociado con la generación de un puñado de hombres y mujeres que están preparados para un vínculo distinto con el trabajo, un vínculo similar al que aludíamos en referencia a las empresas de punta del capital tecnológico: lúdico, imaginativo y pasional.

Foucault llega a empujar hasta sus extremos esta "inversión" en el capital humano, uniéndola a las expectativas de "mejoramiento" que han acunado muchas de las experimentaciones genéticas, bordeando las visiones de la novela futurista de Aldous Huxley, Un mundo feliz: Sin llegar hasta ese punto, podemos dejar al menos planteadas unas preguntas sobre este selecto estrato social, que ha producido una revolución en el proceso de extracción de la plusvalía y que intenta mantenerse: flexibilizando la regulación de los espacios y tiempos de trabajo y de placer (haciendo sus límites difusos), favoreciendo la formación autodidáctica y la experimentación, generando pequeñas comunidades con universos simbólicos compartidos, incentivando la educación personalizada y focalizada, el trabajo en equipo, etc.

Primeramente, ¿cuál es la capacidad de reproducción de este microsistema? Más allá de los intentos por generar las condiciones de producción de la invención que, sin lugar a dudas, dan resultados 
(el trabajo acumulado siempre lo termina dando), el tiempo y el azar que determinan la invención aún son incalculables: muchos de los grandes inventos que revolucionan la tecnología surgen todavía en los lugares más inesperados. Por otra parte, la experiencia de las comunidades científicas de esta última etapa todavía no ha mostrado cómo funciona el traspaso generacional de esas "obsesiones productivas" a sus herederos. En otro orden de las cosas, cabría preguntar ¿qué vínculo se planteará este capital cada vez más hegemónico con la política más allá de su evidente influencia biopolítica? ¿Seguirá utilizando al Estado nación y al capital financiero como garantes de sus acciones? ¿Cuáles son los puntos ciegos de este dominio tecnológico político que pueden volver su increíble poder de circulación contra sí? ¿Tiene un afuera?

Obviamente, la extracción de la plusvalía es bastante menos ambigua en otras clases sociales, sobre todo en las que siguen vinculadas a las ramas primarias y secundarias de la producción; sin embargo, el proceso de informatización ha calado hondo en la cadena social. Veamos. En las últimas décadas se ha desatado una fuerte migración del trabajo de la industria a la rama de los servicios, esto necesariamente ha impactado los modos de concebir al trabajo mismo, trepando un nivel más (en la mayoría de los casos) en la ampliación de la distancia entre el trabajador y la mercancía que produce, cada vez menos tangible. Hardt y Negri nos advierten de esta tendencia a "tratar a la fabricación como un servicio" (2002, p. 250) y de los alcances políticos que esta distancia con lo producido genera; inicialmente, al contribuir a la atomización diferencial de los trabajadores que entorpece cualquier tipo de organización política que no sea sindical. Esta propensión hacia la economía informacional, que tuvo su primer boom con los empleos vinculados al capital financiero, ha encontrado en la propio medio de trabajo, es decir, en el capital tecnológico, su nicho más importante - como venimos afirmando-.

La tarea es informatizar, traducir el universo de lo real al universo de lo virtual. Y la extracción de la plusvalía en este megaproyecto de traducción evidencia condiciones de explotación mucho más difíciles de sortear para una amplia franja social de la clase (media y alta) asalariada. 
En este contexto, la idea del trabajo full time tiene una literalidad avasallante, dado que con el trabajo después del trabajo que posibilitan las condiciones materiales de muchos de estos nuevos empleos es hasta dificultoso diferenciar donde termina la empresa y donde la empresa personal. Este problema encaja, de modo sintomático, con la porosidad del deseo y con la dificultad para imprimir un sentido a la propia vida, imposibilidad que la lógica de la mercancía ha promovido en la producción de subjetividades, al asignarle objetos de deseo medibles e intercambiables.

Por otra parte, estos nuevos trabajos demandan de sus empleados un polifacetismo y una flexibilidad que suponen una sustancial sobreformación previa para manipulaciones repetitivas de símbolos rutinarios (como cargar datos, procesar textos, etc.), que ahondan clasistamente la diferencia entre un trabajador calificado y uno que no lo es, entre un trabajador para el capital simple y uno para el capital potenciado; diferencias que, por otro lado, se encrudecen dependiendo de la geopolítica de la que estemos hablando y la proveniencia identitaria del sujeto en cuestión (es decir, de todos los filtros xenófobos, racistas, machistas y clasistas que la nación, como sistema de exclusión, impone).

En resumidas cuentas podemos, siguiendo los pasos de Hardt y Negri, distinguir tres grandes tipos de trabajo inmaterial que en la era de la informatización están en boga en el campo de los servicios:

El primero está implicado en una producción industrial que se ha informatizado e incorporado tecnologías de la comunicación de modo tal que transforman al propio proceso de producción. [...] El segundo es el trabajo inmaterial de las tareas analíticas y simbólicas, el que subdivide en manipulaciones inteligentes y creativas por un lado y tareas simbólicas rutinarias por el otro. Finalmente, un tercer tipo de trabajo inmaterial implica la producción y manipulación de afectos, y requiere contacto humano (virtual o real), trabajo en modo corporal. Estos son los tres tipos de trabajo que dirigen la posmodernización de la economía global (Hardt y Negri, 2002, p. 255). 
Para que esto pueda ser así, la mayor parte de la población mundial debe trabajar "materialmente" en condiciones cada vez más alienantes. Cuando Marx escribió El capital, e incluso durante bastante tiempo después, uno de los argumentos fuertes para justificar la extracción de la plusvalía del trabajador por el capitalista que construía allí su ganancia fue la teoría del derrame; luego del desarme de la experiencia bienestarista quedó perfectamente claro que "Nunca el desarrollo de la productividad puede beneficiar espontáneamente a la clase obrera" (Althusser, 2004, p. 27); mientras que sí sucede que "el incremento de la productividad del trabajo social se convierte en la palanca más poderosa de la acumulación" (Marx, 2000, p. 374). Medio siglo después de que se desplomara la última intervención organizada del Estado en el capital, las luces de neón del desarrollo productivo no deslumbran a nadie $y$, sin embargo, las recetas políticas de las grandes potencias siguen conjurándolo incluso internamente, frente a la deuda social, como justificativo de su impulso tanático. Principalmente y de modo explícito, para sostener las atrocidades ecológicas (fue de hecho el argumento que Estados Unidos esgrimió para no plegarse al Acuerdo de Kyoto) y de una forma mucho más tácita, por ser políticamente incorrecta, este es el argumento de peso que sostiene la opinión pública de la maniobras de las "guerras justas" en países petroleros, revestida oportunamente de "liberación democrática".

\section{Cuatro. Propensión a la concentración y centralización del capital}

Vengo de un país en donde las cifras ya no quieren decir nada. Bill Gates pesa 90 millares de Euros, o sea el PNB de Haití en los

30 años que siguen [...] Hay países en que los pobres venden sus órganos, o venden sus hijos, o su voto. Y hay otros en donde se especula su consciencia según el curso de la bolsa. ¿Quién dijo que la economía estaba al servicio del hombre? Yo vengo de un país que técnicamente no existe. Como el 2/3 de un planeta que se vendió por un puño de dólares. Raoul Peck, La ganancia y nada más

La cuarta proposición, la tendencia a la concentración y centralización de capital, es la única forma de aproximación a la economía que 
permite estudiar los problemas de cualquier sociedad contemporánea. Para que tengamos una idea del rango de determinación económicopolítica de lo que hablamos, podemos mentar los siguientes datos: en la economía mundial, según CNN Fortune, las tres empresas más ricas (Exxon Mobil, Apple y Gazprom) el año pasado obtuvieron beneficios por 124,7 miles de millones de dólares, y solo la primera de ellas (la petrolera Exxon Mobil) logró un valor en bolsa semejante al PBI de Colombia. Las grandes multinacionales, aliadas del capital financiero y tecnológico, cumplen con las tendencias centralistas y acumulativas transformándose en colosos, con sus tentáculos esparcidos por todo el globo, y únicamente la comprensión de sus interrelaciones con los Estados puede arrojar algo de luz sobre ese concepto tan vidrioso como es el de "soberanía" en tiempos actuales. La caracterización del sistema mundo como un sistema de redes superpuestas es posiblemente el más preciso; en este diagrama la acumulación no se sostiene con la generación espacial de grandes puntos neurálgicos, sino con el dominio de la mayor cantidad de vías de circulación de capitales en sus más diversas formas (información, comunicaciones, materias, finanzas, manufacturas, servicios, etc.).

Pero, obviamente, esta abstracta red de acumulaciones constantes se sostiene con los cuerpos que aplasta, condena a la quiebra a las endebles economías nacionales, afianza los mecanismos perversos de extracción del plusvalor y colabora con engendrar para sus futuros proyectos lo que Marx llamaría sangrienta acumulación primaria, con la guerra como el método más eficaz para lograrla. "La violencia es la comadrona de toda sociedad vieja que lleva en sus entrañas otra nueva. Es, por sí misma, una potencia económica” (Marx, 2000, p. 461). Del mismo modo que la crisis es una de las formas más rápidas en las que se generan acumulación y centralización de capitales (baste ver las escaladas y fusiones que la última crisis produjo en el mercado mundial), la guerra sigue siendo "la comadrona" de las nuevas etapas de la economía que a su vez produce, al reactivar una de las industrias más importantes: la armamentista.

La guerra asegura la conformación geopolítica de un mapa de desigualdades estructurales irreversible; esta es también una novedad con los 
años de El capital: las cientos de generaciones de secciones enteras del mapamundi que se han sucedido con índices de inanición irrecuperables. Según cifras recientemente difundidas por la organización no gubernamental Oxfam, las 85 personas más ricas del mundo tienen una fortuna equivalente a todas las posesiones de la mitad de la población más pobre del planeta. La propagación de estas asoladas que hacen posible el derroche de una nominalmente insignificante cúpula social es posible, entre otras cosas, gracias a la guerra permanente, mediáticamente presentada como guerra democrática contra las tiranías de Medio Oriente que guarda, en el fondo, el mismo paradigma del "progreso" que estaba en boga en el escrito de Marx. Como nos dice Butler (2006), cuando repone la escena de "liberación" de los burkas de un grupo de mujeres afganas:

Según las fotos triunfalistas que dominaban la primera página del New York Times, estas jóvenes desnudaron sus caras como un acto de liberación, como acto de gratitud hacia el ejército norteamericano y como expresión de un placer súbitamente autorizado. El espectador norteamericano estaba listo, por así decirlo, para ver el rostro, y fue por la cámara y para la cámara, después de todo, que el rostro finalmente se desnudó, convirtiéndose en un instante en un símbolo de la exportación exitosa del progreso cultural norteamericano. En ese momento se desnudó para nosotros que, por así decirlo, quedamos en posesión del rostro. No solo fue captado por nuestras cámaras, sino que dispusimos del rostro para captar nuestro triunfo y para justificar nuestra violencia, las incursiones en la soberanía, la muerte de civiles. ¿Dónde están las marcas de la pérdida en esos rostros? ¿Dónde está el sufrimiento por la guerra? (p. 176)

No se trata solo de tomar lo que el capital necesita para mantener su abrumador crecimiento, sino de asegurar que la extracción luego sea agradecida y bendecida por la opinión pública, que ahora sí encontrará en esos Otros solo unos iguales desgraciados por haber nacido en otro sitio y ya no la incómoda alteridad social y cultural. En otras palabras: compartir los mismos deseos, mas no las mismas posibilidades. En este punto es importante advertir que la naturaleza violenta del avan- 
ce voraz del capital para la explotación de nuevos territorios es una constante que se sostiene a pesar de algunos cambios estructurales muy importantes en el papel del capital en la producción de sujetos. Expliquémonos. El éxito del capital no se puede advertir solamente por su capacidad de dominación ideológica que convence a cada cual de las posibilidades y de las imposibilidades, ese es un error grave de cálculos que ha costado más de una derrota política. El capital también supone un complejo y sutil sistema de compensaciones para buena parte de aquellos sujetos que no pueden apuntar a la acumulación. Como lo demuestra Alexander Kluge (2008), en Paradojas de la sociedad de cambio, tercera parte de su maravilloso documental Noticias de la antigüedad ideológica: Marx-Einsestein-El capital, el capital también tiene el sabor de la libertad, o de su espectro.

El capital resemantiza las mercancías permanentemente al constituir una polifonía en torno a ellas (las medias de seda: arte, explotación y moral) y estalla las distancias entre las palabras y las cosas, esto también puede ser una experiencia liberadora. Como la mejor de las teologías, el capital, que no quiere dejar a nadie afuera, no necesita que se crea en él, le basta con que crea él en usted: busca, seduce e induce. El capital, a diferencia de las revoluciones congeladas, presenta un abanico de posibilidades para realizar la libertad de la individualización, y como Marx mismo lo señaló: "el hombre, en el sentido más literal, es un zoon politikon, no solamente un animal sociable, sino un animal que solo puede individualizarse en sociedad" (2003, p. 20). Para muchas personas el capital es la promesa de esta identidad diferencial.

\section{El monopolio de la información y los sentidos}

El conocimiento es libre. Somos Anónimos. Somos Legión. No perdonamos. No olvidamos. ;Esperadnos! Anonymous

La información ha sido siempre un capital muy valioso para la acumulación capitalista; pero en una época en que — como hemos visto- la innovación tecnológica define dramáticamente las posiciones se ha disparado la competencia por este precioso capital. A su vez, el ambi- 
cioso desarrollo de la realidad virtual con sus impresionantes bases de datos nos recuerda todo el tiempo que la puerta a otra situación real "está ahî", en la conexión que habilita un delgado cable de teléfono. Es sencillamente sobrecogedor imaginar que solo un sistema de códigos distinto podría cambiar las condiciones materiales de existencia de millones de personas. Claro que las llaves tienen nombres, los de los bancos y las grandes compañías, lo que ha llevado a un conjunto de personajes a preguntarse ¿y si no fuera por los nombres?

La revolución de la autoría, que empezó con los imprecisos pronósticos foucaultianos de ¿Qué es un autor? (Foucault, 1969) tiene ahora varios adeptos, tanto en el universo real como en el virtual, ambos de una materialidad que ciertamente ha resultado inquietante. Bajo la premisa de que toda autoría supone una violencia fundacional y el primer peldaño de un sistema de control y regulación, tanto los militantes del ciberespacio como los movimientos queers (de travestis, lesbianas, gays y trans) se han dado la política de bombardear el sistema de significaciones dominantes mediante lo que Niklas Luhmann llamaría ruidos. Se trata de un nuevo tipo de resistencia que tiene hacia su interior una gran diversidad de expresiones que conviven apostando al disenso y a la desnormativización, sus características son tan eclécticas y sus programas tan abiertos que aquello que los aglutina epocalmente (como síntoma de este tiempo) es esencialmente el rechazo al monopolio de los sentidos, la formación y la reproducción que tienen el capital y sus aliados. El reclamo contra este monopolio ideológico de control del capital va desde la demanda contra la performatividad sexista de los íconos nacionales, de las prácticas institucionales, de los discursos de los mass media, hasta las encrucijadas en torno a la propiedad intelectual y la mercantilización de la producción del conocimiento. La apuesta es, en todos los casos, a una resignificación del espacio público y a una conquista de la soberanía de nuestros cuerpos (comenzando por el deseo).

El activista Aaron Swartz, quien fue sentenciado por contravenir los derechos de autor de la Ley SOPA, que restringe el acceso a cierta información al arancerarlo, escribió en su Manifiesto de la guerrilla por el acceso abierto: 
Quienes tienen acceso a estos recursos — estudiantes, bibliotecarios, científicos- han recibido un privilegio. Pueden alimentarse de este banquete de conocimiento mientras el resto del mundo es excluido. Pero ustedes no necesitan — de hecho, moralmente, no pueden - mantener este privilegio solamente para ustedes. Tienen el deber de compartirlo con el mundo. Y tienen que compartir claves con sus colegas y llenar solicitudes de descargas para sus amigos. Mientras tanto, aquellos que han sido excluidos no esperan sin hacer nada. Han estado fisgoneando a través de agujeros y trepando cercas, liberando información guardada por las editoriales y compartiéndola con sus amigos. Pero todas estas acciones se quedan en la oscuridad, escondidas en el sótano. Se las llama robo o piratería, como si compartir la riqueza del conocimiento fuese el equivalente moral a saquear un barco y asesinar a su tripulación. Compartir no es inmoral: es un imperativo moral. Solo quienes están cegados por la ambición podrían rehusarse a dejar que un amigo obtenga una copia. No hay justicia al cumplir leyes injustas. Es hora de salir a la luz y, siguiendo la tradición de la desobediencia civil, oponernos a este robo privado de la cultura pública (2008).

Swartz se suicidó hace ya un año, a la edad de 26 años. En ese momento estaba enfrentando una demanda del servidor JSTOR por 35 años de prisión y más de un millón de dólares en multas. Su muerte logró un mártir en tiempo donde esta figura parece completamente anacrónica. Podemos ver este extraño reflujo político de las marcas discursivas de lo político en sentido clásico (moderno) en su discurso, la alusión a la exclusión, a la responsabilidad compartida, a la socialización de la riqueza, al espacio público, al llamamiento a la acción... Signos que parecen anacrónicos en la liquidez posmoderna y que, sin embargo, llegan a convertirse en un factor común de estas luchas. El tono de los manifiestos de Anonymus (quienes como protesta por la muerte de Swartz hackearon la página del Instituto Tecnológico de Massachusetts, que había aportado pruebas ilegalmente para el enjuiciamiento) impacta justamente en esa anacronía. Allí se enuncia una certeza, un fin, las condiciones de los medios, una serie de verdades: hay un programa político. Más allá de las simpatías o los desagrados, hay que reconocer que es un signo completamente novedoso, que conjuga un 
orden del discurso plenamente reconocible para los escuchas con un nuevo sistema de militancia en sintonía con el lenguaje actual del capitalismo. Contra las teorías posfundacionalistas (Marchart, 2009), estos movimientos claramente pretenden fundar, por lo pronto, nuevas subjetividades; el mensaje es inconfundible:

Anonymous es todos y todas partes. No hay líderes, no hay entidad individual dirigiéndonos. Solo la colectiva indignación de individuos guiando nuestra mano en los esfuerzos actuales por generar consciencia [...] la información está allí afuera. Es suya para que la tomen. Ármense con conocimiento (Anonymous, s. f.).

También podemos leer esta expectativa fundacional en las declaraciones del artista peruano Giussepe Campuzano, el creador del Museo Travesti:

[Se busca] recuperar todos los sentidos del travestismo: los condenados, pero también los que se les arrebataron [...] organizar un enfoque multidisciplinario que revelará todas las aristas del "cuerpo como político" (un pastiche de razas, géneros, situaciones y usos) que permita nada menos que fundar una nueva nación para un nuevo cuerpo (Link, 2008).

Actualmente, la lista de países, partidos, bancos y empresas que se ha quejado de ataques de Anonymous luego de algún hecho dramático (por lo general vinculados a decisiones políticas) es realmente importante y cada semana se registran nuevos puntos vulnerados. Así mismo, la expansión de las distintas expresiones de las luchas de género crece a una velocidad inusitada en medio de una reacción bestial. Claramente sus distintos métodos de lucha y programas los enfrenta diferencialmente a las capacidades de reabsorción del capital; sin embargo, es importante registrar sus puntos de contacto en la lucha contra el monopolio ideológico que hace posibles todos los otros, como Marx (2010) había analizado tempranamente en La ideología alemana. 


\section{Cinco. No hay afuera del mercado mundial}

Con la incorporación de China, producto de las reformas planteadas por Deng Xiaoping en 1978, el mercado mundial y el planeta Tierra se volvieron una misma cosa. No hay lugar en este mundo virgen de capitalismo, incluso aquellas comunidades que aparecen en el National Geographic bajo la noticia de no haber visto a un hombre blanco o a una cámara de fotos, están determinados por la lógica del capital, que decidió su olvido, así como mañana puede decidir su emigración o su muerte.

Sabíamos que el capital necesitaba estructuralmente del ingreso a un exterior no capitalista para realizar la plusvalía extraída; también que eventualmente este exterior sería incorporado a la lógica capitalista y utilizado para capitalizar la plusvalía realizada. Hecho que empujaría nuevamente al capital a la búsqueda de nuevos bordes. Esta tenencia que habían analizado detenidamente Marx y Rosa Luxemburgo tiene evidentemente un límite, como la filósofa marxista lo había augurado, y ese límite ya llegó: no hay afuera del mercado mundial. Existen, si se quiere, distintas versiones del capitalismo circulando; pero todas son partes clave de un mismo sistema global. Entonces, la pregunta lógica que aparece es ¿cómo realizar la plusvalía extraída? ¿A quién vender? El desarrollo exorbitante del capital financiero despejó esta encerrona: la plusvalía extraída se invierte en capital financiero, que hasta hace muy poco parecía un mercado autosuficiente. Sin embargo, esta última crisis nos ha notificado que el capital financiero representa casi exclusivamente el capital financiero y que esta gran tautología virtual, en la que las grandes potencias habían decidido apostar, tiene un costo muy alto que los restos gananciales de los Estados no están en condiciones materiales de seguir sosteniendo.

Pero hasta la tercera parte del siglo pasado esto no era así: el capital potenciado era extrínseco, esto es, las ganancias extraordinarias vertían del monopolio político (colonial o poscolonial) y esta situación coincidía con la estructura de poder de la clase dominante, que pensaba este dominio como una extensión de la influencia del Estado nación, con su adentro y afuera. Las teorías de la dependencia acunadas por 
los desarrollistas latinoamericanos en los años sesenta explicaban cómo los países ricos (adentro) se convertían en las metrópolis que manejaban la economía de los países pobres (afuera), viviendo a costa de esta vampírica relación. Si bien en rasgos generales el reparto de la riqueza sigue funcionando representativamente así, el sistema se ha complejizado con los tres elementos que ya hemos mencionado - hegemonía del capital tecnológico, informatización de la producción e ingreso de China al mercado mundial—, y esta distinción entre las partes ya no puede trazarse en esos términos lineales (ha quedado claro que ningún lugar está exento de dependencia, lo que se modifica significativamente es la vulnerabilidad).

En este contexto, repasemos el mejor método para diagramar las relaciones de dominación es una red que puede calcular la capacidad de circulación de sus usuarios y "tejedores" (los que producen red: las comunicaciones). Solo así podemos acercarnos a la comprensión de la consolidación del gigante asiático con una tasa de crecimiento anual imbatible, ${ }^{2}$ que se convierte en el primer exportador del planeta, el mayor acreedor de la deuda norteamericana, ${ }^{3}$ que se perfila como primera potencia mundial y sin poseer, ni aspirar, al monopolio político (al menos en términos clásicos, es decir, a la formación de hegemonía en sentido gramsciano).

¿Qué tendencia podría explicar esta reconfiguración de la expansión del capital capaz de borrar la barrera entre el adentro y el afuera del mercado mundial? En palabras de Alejandro Horowicz, esto teóricamente se explica porque "la gramática homogeneizante de la mercancía chocaba con la lógica de inclusión y exclusión social” (2003, p. 92) e histórico políticamente del siguiente modo:

Como el proletariado no fue capaz de vencer en el periodo anterior, fue vencido en el siguiente por una pinza infranqueable: de

\footnotetext{
2 El producto interno bruto chino pasó de 420.000 millones de dólares en 1980 a 5,6 billones de dólares en 2002, esto es, creció 13 veces en 22 años. En el 2011 era de 11,44 billones y le pisaba los talones a Estados Unidos, con 15,29 billones (Le Monde Diplomatique, 2013).

31164 billones de dólares (Le Monde Diplomatique, 2013).
} 
un lado, los esclerosados partidos comunistas europeos, que solo impulsaban un reformismo modernizante patético; por el otro, el capital globalizado, el capital tecnológico. En el marco de esta colosal derrota histórica, el capital quebró definitivamente ese adentro-afuera del Estado nacional, estableciendo un adentro del capital, un nuevo mercado mundial para un nuevo proletariado. Nada, definitivamente, resulta extrínseco, ni al capital ni al proletariado; todo, definitivamente todo, es inmanente (Horowicz, 2003, p. 93).

Quedará pendiente analizar ¿qué características tendría este proletariado hoy? — cuando la categoría clásica ha quedado obtusa para la masa mayor de trabajadores-; pero, más allá de esto, la inmanencia del capital y de cualquier programa que le quiera hacer frente es clave (como lo evidencian, por ejemplo, las proclamas de los ciberactivistas con "la revolución desde adentro"). Esto no quiere decir que los Estados nacionales no sigan organizando sistemas de exclusión, o de "inmunización” como diría Roberto Esposito, sino que dicha lógica ya no es extensible a la matriz del capital que hace todas sus distinciones hacia su interior. Distinciones que, evidentemente, son más determinantes y capilares que cualquier medida tomada por los Estados nacionales, porosos garantes de esta segmentación.

\section{Conclusiones}

"Un clásico es un libro que nunca termina de decir lo que tiene que decir. [...] Un clásico es una obra que suscita un incesante polvillo de discursos críticos, pero que la obra se sacude continuamente de encima" (Calvino, 1994, p. 13). Es innegable que El capital cumple con estos dos síntomas que Italo Calvino nos ha procurado para reconocer a un clásico, y esto no se debe tan solo a la increíble naturaleza prospectiva del texto, sino a la genuina preocupación por el devenir de lo humano que encontramos en sus preguntas. De las cinco proposiciones que hemos analizado, de manera macro, en este artículo hemos mostrado que tres siguen en plena vigencia, con las actualizaciones pertinentes, y dos necesitan ser superadas en cuanto principios explicativos de la contemporaneidad; sin embargo, todas ellas nos legan preguntas que 
todavía nos hacen pensar, y en este sentido "nunca termina de decir". Por otra parte, no hay obra filosófica que haya sido la cantera de tantas reescrituras y, por ende, de tantas interpretaciones — entre ellas las más interesantes suelen ser las más irreverentes con el texto... de las "malas lecturas” se organizan las revoluciones, diría Horacio González-; no obstante, después de siglos de manoseo intelectual, esta obra no deja de emerger y sacudir sus propias palabras capturando, como en un repetido natalicio, nuevas miradas. La historia no deja de consagrar a El capital como un dador de sentido, esto explica que, desatada la última crisis, el libro haya llegado a ser un bestseller que impuso al mercado editorial de cientos de países reediciones.

La falta de intentos explicativos totalizantes, en el marco de una crisis global sin precedentes, nos enfrenta a fragmentos desperdigados de explicaciones parciales para hechos superficialmente inconexos; el intento de este artículo ha sido utilizar las certezas de la última gran matriz política explicativa para conectar estos hechos. Se trató de poner en tensión tanto la verdad de la matriz como la naturalidad de los acontecimientos. Este es el único modo posible de analizar acontecimientos que tenemos tan cercanos, que performatean nuestra existencia, intentando exceder el plano de la descripción sin caer en presagios superficiales.

En este punto, comprender el lugar de un tipo particular de capital, cuya lógica ganancial y biopolítica lo perfila como hegemónico; intentar avizorar los puntos en común de las formas de resistencia que ya no se mueven en los márgenes, sino en el centro mismo de la escena, tratando reconfigurar las reglas de juego; actualizar la vigencia del fetichismo como factor fundamental de la comprensión de las relaciones intersubjetivas y probar entender los motivos del éxito de las nuevas forma comunales (que hoy, más que nunca, giran en torno a una falta constitutiva), son todos esfuerzos que una lectura crítica de El capital puede poner en contacto otorgándoles la materialidad y trascendencia de la historia. Lo que es toda una puerta en momentos cuando el sacrificio como mecanismo sistémico borra permanentemente las condiciones políticas que lo hacen posible, así como la memoria de 
lo que se está aniquilando para que todo funcione. En palabras de Roberto Esposito (2003):

Lo que se sacrifica es precisamente el cum que es la relación entre los hombres, y por lo tanto, en cierto modo, a los propios hombres. Paradójicamente, se los sacrifica a su propia supervivencia. Viven en y de la renuncia a convivir. Imposible no reconocer el residuo de irracionalidad que se insinúa en los pliegues del más racional de los sistemas: la vida es conservada presuponiendo su sacrificio; la suma de renunciamientos de que se compone la autorización soberana (p. 42/3).

\section{Referencias}

Althusser, L. (2004). Para leer El capital. México D. F.: Siglo XXI.

Butler, J. (2006). Vida precaria: el poder del duelo y la violencia. Buenos Aires: Paidós.

Calvino, I. (1994). Por qué leer los clásicos. México D. F.: Tusquets.

Debord, G. (1967). La societé du spectale. París: Buchet-Chastel.

Esposito, R. (2003). Communitas: origen y destino de la comunidad. Buenos Aires: Amorrortu.

Foucault, M. (1969). Qu'est- ce un auteur ? París: Bulletin de la Société Francaise de Philosophie.

Foucault, M. (2007). Nacimiento de la biopolitica: curso en el Collége de France (19781979). Buenos Aires: Fondo de Cultura Económica.

Hardt, M. y Negri, A. (2002). Imperio. Buenos Aires: Paidós.

Horowicz, A. (2003). Piezas para rearmar un puzzle. En Diálogo sobre la globalización, la multitudy la experiencia argentina. Buenos Aires: Paidós.

Kluge, A. (2008). Paradojas de la sociedad de cambio (183'). Berlín: Suhrkamp Verlag.

Le Monde Diplomatique. (2013). Cbina: la dueña del futuro. Buenos Aires: Le Monde Diplomatique.

Levín, P. (1997). El capital tecnológico. Buenos Aires: Catálogos.

Link, D. (23 de julio, 2008). Historia americana. Página 12. Recuperado de http://www.pagina12.com.ar/diario/suplementos/soy/1-1510-201007-23.html 
Marchart, O. (2009). Elpensamiento político posfundacional: la diferencia política en Nany, Lefort, Badiou y Laclau. Buenos Aires: Fondo de Cultura Económica.

Marx, K. (2000). El capital. Madrid: Akal.

Marx, K. (2003). Contribución a la crítica de la economía política. México D. F.: Siglo XXI.

Marx, K. (2010). La ideología alemana. Buenos Aires: Siglo XXI.

Mensajes de Anonymous. (s. f.). Anonymous Argentina. Recuperado de http:/ / anonymousdeargentina.blogspot.com.ar/p/mensajes-deanonymous-chanology.html

Swartz, A. (2008). Manifiesto de la guerrilla por el acceso abierto. Recuperado de http:/ / openaccessmanifesto.org/manifiesto-de-la-guerrilla-por-elacceso-abierto/

Toffler, A. (1981). La tercera ola. Bogotá: Edinal.

Žižek, S. (2003). El sublime objeto de la ideología. Buenos Aires: Siglo XxI. 